\title{
Obesidade Infantil a Partir de um Olhar Histórico Sobre Alimentação
}

\author{
Priscilla Machado Moraes" \& Cristina Maria de Souza Brito Dias ${ }^{\text {** }}$ \\ Universidade Católica de Pernambuco, Recife, Brasil
}

\begin{abstract}
RESUMO
Este artigo apresenta uma revisão sobre a história da alimentação e sua influência no desenvolvimento da obesidade infantil. Percorre diferentes momentos históricos, acompanhando as principais transformações ocorridas na sociedade e, como consequência, na alimentação das famílias. Fundamenta-se teoricamente no pensamento sistêmico por entender que, através dessa visão, se tem uma melhor compreensão do processo em que essas mudanças ocorreram. Conclui-se que as modificações no modo de vida das famílias, no contexto sociocultural, progresso de urbanização e industrialização, sedentarismo, influência da mídia e aumento da ingestão calórica contribuem para a incidência do excesso de peso nas crianças.
\end{abstract}

Palavras-chave: obesidade; criança; alimento; família.

\begin{abstract}
Childhood Obesity: A Historical Perspective About Feeding

This article presents an overview of the history of feeding and its influence on the development of childhood obesity. We analyze different historical moments, following the major transformations in society and, as a consequence, in the household diet. The article is theoretically based on systems theory, because the authors propose that through this vision one has a better understanding of the process in which these changes occurred. We conclude that changes in the modes of family life, in the sociocultural context, progress of urbanization and industrialization, sedentary lifestyle, media influence and increased caloric intake contributes to the incidence of overweight in children.

Keywords: obesity; children; food; family.
\end{abstract}

Entre todas as alterações que ocorrem no organismo humano, possivelmente a obesidade é a situação mais complexa e de difícil entendimento. Ela é definida como o anormal ou excessivo acúmulo de gordura, uma doença, uma síndrome, um aspecto do nosso metabolismo ou a falta de controle sobre o comer (Fisberg, 2004; Organização Mundial de Saúde, 2006). É sabido que se vive em um mundo onde se define o normal como um conceito estatístico, em que os extremos são vistos como diferentes e com preconceito. Altos e baixos, magros e gordos, toda disparidade é arriscada. Os indivíduos que se inserem nessas categorias enfrentam problemas diários (Fisberg, 2004).

Hoje os obesos são um problema não somente de países industrializados, mas também de países em desenvolvimento, que passaram a enfrentar, junto com a desnutrição, a obesidade. Esta última é, provavelmente, uma das enfermidades mais antigas do homem. Os relatos sobre ela remontam aos tempos de Hipócrates (460-377 a.C.). Entre as citações do referido médico estão a obesidade, descrita como doença, e suas sugestões de medidas terapêuticas são iguais às de hoje: trabalho, exercícios, caminhadas e ingestão menor de alimentos (Setian, 2007).

As escolhas alimentares do homem e sua diversidade são únicas entre os primatas. Isso revela a importância da compreensão sobre as transformações ocorridas no decorrer dos tempos. Segundo Perlès (1998), embora os historiadores estejam em condições de reconstituir e interpretar em detalhes os gestos mais sutis na fabricação de uma ferramenta de pedra, por exemplo, não podem esboçar - no que se refere à his-

* Endereço para correspondência: Priscilla Machado Moraes - pris25@globo.com

** Endereço para correspondência: Cristina Maria de Souza Brito Dias - cristina_britodias@yahoo.com.br 
tória da alimentação - mais que um panorama muito geral e hipotético.

Acredita-se que a modificação dos hábitos alimentares ocorre através de um processo sistêmico, em que a evolução da humanidade teve um papel importante $\mathrm{e}$ complexo sobre as demandas da alimentação na contemporaneidade. As tribos nômades, dos povos primitivos, seguiam de lugar a lugar em busca de alimento. $\mathrm{O}$ processo de seleção natural favoreceu aqueles que conseguiam sobreviver com um suprimento alimentar reduzido, que apreciavam os alimentos com taxa alta de calorias, podiam sentir de longe o cheiro do alimento e suportar temperatura fria. À medida que as épocas passaram, os humanos desenvolveram características genéticas múltiplas, que lhes permitiram sobreviver com uma quantidade limitada de alimento e favorecer o desenvolvimento da gordura subcutânea (Collipp, 1977).

Hoje, a maioria dos descendentes modernos desses bem-aventurados sobreviventes dispõe de um suprimento generoso de alimentos, roupas adequadas e sistemas de aquecimento. Portanto, segundo Collipp (1977) aqueles traços que há muito tempo favoreceram a sobrevivência são agora inúteis e, provavelmente arriscados, visto que podem acarretar danos à saúde da população, e entre esses se encontra o fenômeno da obesidade.

Considerando que a base etiológica da obesidade é multifatorial, o objetivo deste trabalho consiste em uma revisão sobre a história da alimentação e sua influência no desenvolvimento da obesidade infantil. Propõe a compreensão de alguns acontecimentos socioculturais que podem ter contribuído para o estilo de alimentação das famílias, acarretando o referido fenômeno. A pesquisa está alicerçada em material bibliográfico coletado entre os anos de 1970 a 2010, totalizando 37 referências que foram analisadas e avaliadas quanto à sua contribuição para o mencionado objetivo. A base teórica adotada neste artigo é o pensamento sistêmico, por privilegiar a compreensão dos indivíduos através do estudo das suas relações com o meio familiar e social.

\section{REMONTANDO À HISTÓRIA}

A Pré-História pode ser dividida em três fases: Paleolítico, Mesolítico e Neolítico, sendo caracterizados dessa forma:

Paleolítico ou Idade da Pedra Lascada - durante esse período, a principal atividade do ser humano era a caça de animais para sua alimentação e produção de vestimentas, bem como coletar frutos e raízes para complementar sua alimentação. Ele já tinha domínio sobre o fogo e mostrava uma articulação da linguagem. Foi um período marcado pelo nomadismo, ou seja, elevada atividade em busca dos meios de sobrevivência.

A carne e os alimentos estocados eram consumidos secos ou reidratados através da fervura: pela ebulição que se processava em recipiente de madeira, de cascas ou de pele, onde se jogavam, de quando em quando, pedras aquecidas, cujos vestígios foram perfeitamente preservados junto às fogueiras; ou pela ebulição direta no fogo, no estômago ou em peles de animais. Além disso, assavam-se grandes pedaços de carne em espetos, costume que pode ser observado nos tempos atuais, caracterizado pelo tipo de comida conhecida como churrasco. Os pedaços menores podiam ser assados diretamente sobre as pedras usadas na maioria dos fogos que se acendiam nesse período (Franco, 2004; Perlès, 1998).

Mesolítico: nesse período intermediário, o homem conseguiu dar grandes passos rumo ao desenvolvimento humano e à sobrevivência, de forma mais segura. O domínio do fogo foi o maior exemplo disso. A alimentação, em contraste com a do final do paleolítico, distinguiu-se por uma grande variedade de espécies vindas de habitats diferentes, que podiam ser explorados a partir do espaço geográfico em que fixavam suas moradias: como peixes, moluscos, pássaros. $\mathrm{O}$ consumo de carne diminuiu pela substituição dos animais maiores pelos menores, uma vez que aqueles são mais difíceis de capturar na profundeza da floresta. Outros dois grandes avanços foram o desenvolvimento da agricultura e a criação de animais. Cultivando a terra e criando animais, o homem conseguiu diminuir sua dependência com relação à natureza. Esse período foi marcado pelo início do sedentarismo, pois a habitação tornou-se fixa. Surgiram as comunidades, e houve também a divisão do trabalho por sexo, quando o homem ficou responsável pela proteção e sustentação da família, enquanto a mulher ficava encarregada da criação dos filhos e cuidados da casa (Franco, 2004; Perlès, 1998)

Neolítico: aqui o homem atingiu um importante grau de desenvolvimento humano e estabilidade com os instrumentos da caça. Com a sedentarizarão, a criação de animais e a agricultura em pleno desenvolvimento, as comunidades puderam trilhar novos caminhos. Os principais alimentos cultivados eram: trigo, cevada, milho, arroz, mandioca e batata-doce. Houve o desenvolvimento e a criação de objetos de metais, 
tais como: lanças, ferramentas e machados. Os homens puderam caçar melhor e produzir com mais qualidade e rapidez. A produção e a armazenagem de alimentos garantiam o sustento necessário para os momentos de seca ou inundações. Com o desenvolvimento agrícola, as comunidades foram crescendo e surgiu uma necessidade de troca entre vilas e pequenas cidades, acarretando a variação do consumo de produtos (Franco, 2004; Perlès, 1998).

Desde o período paleolítico, as escolhas alimentares se diversificaram e orientaram as estratégias econômicas, ao mesmo tempo em que eram influenciadas por elas. Para os autores acima citados, muitos são os alimentos que permitem atender às necessidades dietéticas do homem, e é provável que - desde essa época as preferências culturais e os gostos transmitidos de geração a geração tenham prevalecido. Assim, o que se observa é que mesmo a alimentação pré-histórica não respondeu exclusivamente às necessidades nutricionais, mas também às necessidades individuais. A alimentação tornou-se, progressivamente, elemento essencial da estruturação dos grupos, da expressão de uma identidade própria e origem de um pensamento simbólico (opções por determinados alimentos, maneira de consegui-los, modalidades de preparação e receitas culinárias).

Simultaneamente ao desenvolvimento da espécie humana, se desenvolvia o sistema familiar. Ariès (2006) assinala que, na Idade Média, a família cumpria uma função de assegurar a transmissão de vida, dos bens e dos nomes, mas não havia ainda um sentimento de família e infância, com suas particularidades distintas que se conhece hoje, de espaço privado, de intimidade. A vida social, ou seja, o espaço coletivo era o lugar onde se desenrolavam as principais formas de relacionamentos e trocas. A família era uma realidade moral e social, mais do que sentimental.

Ainda, segundo o autor, foi a partir do século XVII que a expressão da infância começou a adquirir o sentido que hoje se lhe atribui, e foi somente no século XVIII que a família tornou-se um agrupamento íntimo onde seus membros deveriam permanecer. Antes dessas transformações, as crianças participavam da vivência coletiva e sua criação não se dava no seio da família, sob a responsabilidade dos pais. Quando tinham aproximadamente sete anos, meninos e meninas eram afastados de sua família de origem e enviados a outras casas para que realizassem e aprendessem trabalhos domésticos e, dessa forma, eram inseridos no mundo adulto.
A família transformou-se profundamente, na medida em que modificaram-se as relações internas com a criança. Começou a se produzir um sentimento de família, em lugar da tão privilegiada vida coletiva. Assim, além de servir de veículo de transmissão dos bens e do nome, a família assumiu uma função moral e espiritual, adquirindo uma responsabilidade maior em relação a suas crianças (Ariès, 2006; Chaves, Borrione, \& Mesquita, 2004). Dessa época em diante, a educação passou a ser fornecida pela escola e, juntamente com a família, a criança foi sendo retirada, gradativamente, do mundo adulto, e a ela foi reservado um espaço específico dentro da sociedade, em que se delimitam as diferenças e as necessidades da fase da infância. Assim, a nova sociedade destina a cada etapa da vida um espaço reservado (Ariès, 2006; Chaves \& cols., 2004).

Hoje, espera-se que a família seja a principal responsável pelo desenvolvimento da criança, assegurando a transmissão de afetos, acolhimento, bem- estar, promovendo proteção e segurança aos seus integrantes. Nesse contexto, a infância, que passou a ser contemplada como um estágio mágico de alegrias e divertimento do ciclo vital, começou a ser ameaçada pelas patologias contemporâneas, como é o caso da obesidade e suas consequências. Nesse cenário, a epidemia da obesidade infantil surge como um desafio do século XXI, não somente para as famílias que lidam com o problema, pois necessitam de constantes adaptações, mas também para toda a comunidade científica que se dedica ao entendimento desse fenômeno.

\section{SOCIEDADE E TRANSIÇÃO ALIMENTAR}

Devido à dificuldade de encontrar literatura que fizesse um percurso sobre o desenvolvimento da alimentação infantil, será realizado um panorama geral do ato de alimentar, atrelado aos aspectos culturais de toda população.

De acordo com a Teoria Sistêmica, pode-se compreender a sociedade como um conjunto de pessoas que formam um sistema aberto, onde suas interrelações são feitas com indivíduos pertencentes ao mesmo grupo, mantendo um contínuo intercâmbio com o meio. Ou seja, pode-se considerar uma sociedade como um sistema composto de vários subsistemas que são interdependentes. Por um lado, refletindo sobre as mudanças sociais relacionadas ao corpo, a aparência feminina, na Idade Média, estava direcionada à mulher branca e pura, com o corpo virginal e delicado, esguio e gracioso, com ombros ligeiramente caídos, busto comprido, membros longos, pés grandes, 
quadris arrebitados, ventre arredondado e proeminente sob uma cintura fina. Esta é a mulher das cantigas de amor e dos romances corteses que permearam o período. Por outro lado, datam do século XIII os níveis extremos de magreza, refletindo autossacrifício, com ingestão somente da Eucaristia, considerada com um profundo significado espiritual, que caracterizam as santas medievais (Assumpção, 2004; Weinberg, 2010).

No Renascimento, alteram-se as concepções do belo e o novo olhar traz de volta a mulher em um corpo glorificado como o mais esplêndido da criação, dada a harmonia de suas proporções. Privilegiava-se o corpo feminino com formas arredondadas, matronais e sensuais ao mesmo tempo. No entanto, com o passar dos séculos, as migrações, a capacidade de organização humana, o fim do nomadismo determinam mudanças na aparência corporal. A causalidade circular dos acontecimentos como as guerras, períodos de carência, fixação no campo, contribuíram para delinear uma maior proporcionalidade nas características corporais do ser humano (Fisberg, 2004).

Com a Revolução Industrial, o desenvolvimento das indústrias alimentícias acarretou novos rumos, modificando definitivamente os comportamentos sociais e os hábitos alimentares das pessoas. $\mathrm{O}$ que era desenvolvido artesanalmente como farinha, óleos, açúcar passou a ser fabricado por grandes usinas que se expandiram por todo o mundo. As mulheres passaram a fazer parte da força do trabalho, o que levou a modificações na vida doméstica (Ramos \& Storel, 2001).

No ano de 1830, os primeiros colonos europeus constataram que - nas colônias americanas - os indivíduos eram bem mais alimentados do que os da pátria mãe; assim começaram a imigrar para os Estados Unidos. Os progressos consideráveis dos transportes, estradas, canais, navios a vapor e da agricultura começaram a transformar a economia de subsistência, que tinha caracterizado a maioria das fazendas do país, em economia de mercado, e a estimular o rápido crescimento do comércio e da indústria. Daí em diante, uma variedade de gêneros alimentícios estava disponível por períodos do ano muito mais longos. Surgiu a primeira reforma alimentar com conselhos pseudocientíficos para se evitar alguns alimentos aos quais a ciência atribuía efeitos nocivos (Levenstein, 1998, 2003a, 2003b).

Os europeus, que chegam aos Estados Unidos pela primeira vez, ficam impressionados com o número de obesos que encontram nesse país e não deixam de observar que os americanos são, aparentemente, nutridos demais. Se a aversão pela corpulência é um fenômeno bastante recente, a imagem da América onde reina a abundância alimentar não o é. Desde o início, os americanos consideraram-se, com orgulho, "o povo da abundância" e, especialmente, da riqueza nutricional. A América foi também a pátria de inúmeros métodos que visavam limitar o consumo dessa profusão de alimentos, desde as manias alimentares mais bizarras ("vitaminomania": equivalência química entre todas proteínas em substituição ao consumo de carne), até as teorias científicas mais sensatas e respeitáveis ("Negative Nutrition": advertências contra o consumo exagerado de certas categorias de alimentos, a fim de se evitar prejuízos à saúde, como as gorduras - elevação do colesterol; o sal - prejudicial à pressão arterial; o açúcar - desencadeador da diabetes) (Levenstein, 1998, 2003a, 2003b).

Nesse panorama, a segunda revisão dos hábitos alimentares aconteceu com o movimento da reforma dietética, que se manifestou na transição do século XIX para o XX, e apoiava-se em novas ideias científicas que, supostamente, deveriam contribuir para a melhoria da saúde e, ao mesmo tempo, da moralidade do país. A preocupação inicial dos reformadores sociais e especialistas em economia doméstica não estava direcionada à burguesia, classe média ou fazendeiros, e sim em convencer as famílias da classe operária a gastar menos do orçamento com alimentos. Assim, eles poderiam reservar mais dinheiro para gastar com alojamento e vestuário, visto que viviam em condições precárias, empilhados em moradias insalubres e mal-aquecidos (Levenstein, 1998, 2003a, 2003b). O que se percebe aqui é que a transição nutricional esteve correlacionada, primeiramente, com mudanças sociais, econômicas e demográficas e, posteriormente, com interesses na saúde.

O século XX foi marcado por duas grandes guerras e a divisão dos países por blocos econômicos. A fome atingiu diversas sociedades, e a entrada dos Estados Unidos na Segunda Guerra Mundial gerou uma preocupação no país em relação à penúria alimentar e ao racionamento, visto que, impedir ou racionar a compra dos alimentos preferidos pelos americanos era esbarrar de frente com a imagem da sua pátria como o verdadeiro país da abundância. $\mathrm{O}$ ressentimento surgido durante o conflito persistiu por alguns anos (Levensteisn, 1998, 2003a, 2003b). Ao mesmo tempo, alguns problemas de saúde começaram a ser relacionados à falta ou ao excesso de nutrientes, como a ausência de ferro, que produz anemia; ou o excesso de 
sal, que favorece a hipertensão arterial. O aleitamento materno e a inclusão de outros alimentos na dieta alimentar das crianças foram apontados como maneiras de se evitar o óbito infantil. Com isso, iniciou-se uma preocupação pela qualidade de vida da criança e do adolescente (Espaço Ciência Viva, 2010).

Após 1948, uma aparência de ordem foi restaurada nos mercados e as pessoas voltaram a ter a impressão de que estavam vivendo na abundância. Assim, as preocupações com a higiene dietética foram relegadas para segundo plano. Entre 1946 e 1963, a era do baby boom, foi marcada pela formação de várias famílias americanas preocupadas em se adaptar à nova realidade. No plano alimentar, as questões de saúde e gastronomia cederam lugar à comodidade, marcando o início do que os fabricantes de alimentos industriais designaram de "comida pronta a servir" (Levenstein, 1998, 2003a, 2003b). O referido autor salienta que, foi nesse momento que os produtores e especialistas na transformação alimentar aperfeiçoaram uma grande quantidade de métodos de cultivo, criação de gado, preparação prévia, conservação e embalagem dos alimentos. Aproximadamente entre 1949 e 1959, os químicos apresentaram, por sua conta, mais de 400 novos aditivos para permitir que os alimentos ficassem em condições de resistir a tais procedimentos. Nesse período, iniciava-se então, pela modernização e fecundidade do espírito americano, a era dos condimentos químicos, tão controvertidos e, por vezes, combatidos pelos profissionais da saúde nos dias atuais.

O século XIX trouxe em seu bojo a mulher burguesa, bem alimentada, roliça, com costas gordas, ombros caídos, cintura grossa, coxas redondas, seios generosos, caracterizando a mãe de família e mulher honesta. A primeira década do século XX correspondeu a uma extensão do século anterior, ou seja, persistiram as silhuetas rechonchudas, redondas. Nos anos posteriores, estruturaram-se as modificações da beleza estética através dos padrões culturais influenciados pela busca incessante de um corpo magro, atlético e de formas definidas. Nesse cenário, os obesos passaram à condição de homens e mulheres rejeitados pela sociedade, ou seja, de padrão de beleza, a figura obesa hoje se constitui em vilã (Fisberg, 2004; Novaes, 2010). Foi nesse contexto de profundas transformações sociais que, após a Segunda Guerra Mundial, ocorreram mudanças no perfil epidemiológico dos países que propiciaram a prevalência de algumas doenças não transmissíveis, como a obesidade, e ampliaram-se as correlações causais com a alimentação, redução da atividade física e outros aspectos vincula- dos à vida urbana. Em termos econômicos, o período após 1945 caracterizou-se como "os anos dourados do capitalismo", marcados pela criação de novos mercados e repetidos ganhos de produtividade industrial (Tardivo \& Falcão, 2006).

Com o avanço da industrialização e da economia de troca em um mercado sistematicamente global, surgiram as redes de fast-food de inspiração norte americana, tratando-se de verdadeiros centros comerciais de alimentação num espaço único. "Nele é proposto toda espécie de fórmulas rápidas: pizzas ou o trio refrigerante-hambúrguer-batata-frita" (Fischler, 1998 , p. 852). Segundo tal autor, a rentabilidade do fast-food deveu-se à presença maciça de jovens, somada à "modernidade" como a eliminação dos talheres e pratos, substituindo-os por embalagens de papelão e sacos de papel. Outro triunfo, é que se transformou em lugar apropriado não somente para os jovens, mas também para as famílias e crianças. Estas últimas tornaram-se $\operatorname{logo}$ a clientela mais assídua, arrastando atrás de si os adultos. Depois dos Estados Unidos, o fast food começou sua expansão mundial, com uma aceitação diferenciada. No entanto, as maiores críticas se direcionaram para as redes de MacDonald's, que caracterizavam o "imperialismo americano", uma ameaça às tradições culinárias da Europa. O hambúrguer foi visto como responsável por toda desordem nutricional constituindo um perigo para a saúde dos jovens. No entanto, a pizza já tinha atingido seu apogeu na Europa, sendo comercializada em padarias, mercearias e por vendedores ambulantes, mas ainda assim, escapava da maioria das críticas (Fischler, 1998; Gòes, 2005).

Em sentido oposto, Franco (2004) defende que o fast food não pode ser considerado mero indício de regressão alimentar, pois apresenta um aspecto funcional inegável: satisfaz a necessidade atual de rapidez e responde à demanda de relações impessoais decorrentes da cultura urbana e do seu ritmo. Para o autor, sua proliferação se justifica também pela emancipação e autonomia financeira da juventude, pela distância entre a casa e os locais de trabalho, estudo e lazer, como também pela dificuldade em conciliar horários em que todos os membros da família possam realizar as refeições juntos. Além disso, o referido autor considera que, para o jovem, comer fora de casa é sinal de independência.

O que fica claro - dentro desse panorama do processo de modernização e ampliação das transformações sociais e práticas alimentares - é que, tanto os sistemas familiares como a sociedade em geral tive- 
ram que utilizar funções que o pensamento sistêmico considera de auto-organização para adaptarem-se ao movimento histórico (Vasconcellos, 2009).

\section{HÁBITOS ALIMENTARES NO BRASIL E SUAS IMPLICAÇÕES NA OBESIDADE INFANTIL}

Até agora, ficou evidente que a alimentação é uma necessidade básica permeada por processos históricos referentes ao desenvolvimento econômico, cultural e demográfico de cada nação. Assim, o ato de comer não representa apenas o fato de reunir elementos nutritivos importantes para o organismo; mas, antes de tudo, é um ato social que expressa o mundo da necessidade, da liberdade e da dominação (Tonial, 2001). Para Philippi (2008) os hábitos alimentares podem ser entendidos como as preferências alimentares que fazem parte da cultura de um povo e são estabelecidos na infância, tornando-se comuns no decorrer da vida. Fischler (1998) também acredita que a socialização alimentar começa na infância, através da família, onde o bebê é estimulado a experimentar alimentos consumidos na cultura onde está inserido. Ou seja, a constituição dos hábitos alimentares tem seu começo no momento em que as práticas de alimentação familiares começam a ser percebidas pela criança. $\mathrm{O}$ crescente acesso das mulheres - nos países desenvolvidos do Ocidente, à atividade profissional - tornou o tempo doméstico precioso. Além disso, o homem, de maneira geral, não tem uma participação maior do que anteriormente nas tarefas de casa (Jablonsky, 2007). Simultaneamente, os equipamentos das cozinhas evoluíram, como: geladeiras, forno microondas, liquidificadores, batedeiras e panelas de pressão, simplificando o trabalho. A mecanização dos trabalhos domésticos refletiu-se nos atuais hábitos alimentares e na estrutura da vida familiar e social moderna.

$\mathrm{O}$ avanço da economia no Brasil é um marco importante na história da alimentação no país, pois o primeiro salário mínimo, instituído em 1940, por Getúlio Vargas, teve como base de cálculo o que se convencionou chamar de cesta básica. Na economia brasileira, o processo de industrialização teve seu crescimento a partir da década de 70. Acrescenta-se ao contexto econômico atual e no final do século XX o Plano Real, que deu início a fortes mudanças na economia e propiciou um aumento real do poder de compras. O sistema capitalista de produção, a economia de mercado e a urbanização induziram uma mudança nos padrões de vida e comportamentos alimentares das populações, principalmente devido à rapidez e à facilidade com que o brasileiro absorve itens das culturas americanas e europeias, por serem considerados modos de vida "superiores" (Ansaloni, 2008; Tardivo \& Falcão, 2006).

No Brasil, com base nas Pesquisas de Orçamento Familiar (2004), do Instituto Brasileiro de Geografia e Estatística (IBGE), realizadas em 1960, 1980 e 2004, verificou-se que as mudanças no padrão alimentar do brasileiro, nos últimos 30 anos, abrangeu toda a população urbana do país. A taxa de obesidade e sobrepeso da população brasileira atinge $40,6 \%$ da população adulta, sendo $11 \%$ desses (10,5 milhões) de obesos. A incidência de indivíduos com sobrepeso ou obesos é maior em pessoas com menor ou nenhuma escolaridade.

Isso se explica porque, nos países em desenvolvimento, o tipo de alimento consumido na zona rural apresenta-se diferente daquele consumido na zona urbana, numa relação diretamente proporcional ao poder aquisitivo ou ao nível socioeconômico. A população urbana, de baixa renda, apresenta uma ingestão calórica inferior quando comparada à população rural. Ela acaba consumindo maior quantidade de alimentos processados, como é o caso da salsicha e da linguiça, ou seja, elege os alimentos que conferem uma sensação máxima de saciedade, sendo palatáveis e de menor custo. Deve-se também considerar os avanços na tecnologia de conservação, armazenamento e transportes de alimentos que, superando as fronteiras, distribui pelo mundo enlatados, conservas, refrigerantes, ketchup, hambúrgueres, pizzas (Tardivo \& Falcão, 2006).

De acordo com Garcia (2003), a empresa de pesquisa de mercado Datamark Ltda - Market Intelligen$c e$, a qual se utiliza de embalagens para fazer suas estimativas, diz que houve um incremento importante na produção dos embutidos, principalmente a salsicha e a linguiça que, durante a década de 80 , tiveram sua produção duplicada. Até 1996 foi multiplicada por 2,8 e 2,3, totalizando uma produção anual de 221.588 toneladas de salsichas e 238.866 toneladas de linguiça.

Os alimentos congelados cresceram $126 \%$ no período de 1990 a 1996 (totalizando, em 1996, uma produção de 46.141 toneladas). Em 1980, eram produzidas 20.095 toneladas de salgadinhos industrializados; em 1996 esta produção foi 6,2 vezes maior. A produção de refrigerante cresceu nos últimos dez anos $90 \%$; e de 1990 a 1996 a produção de biscoitos aumentou $108 \%$. (p. 4)

É nesse contexto que o aumento da prevalência da obesidade no Brasil torna-se ainda mais preocupante, ao se verificar que esse acréscimo, apesar de estar 
distribuído em todas as regiões do país e nos diferentes estratos socioeconômicos da população, é proporcionalmente mais elevado entre as famílias de baixa renda (Ansaloni, 2008; Monteiro \& Conde, 1999). Embora a concentração de renda no Brasil não permita falar em mercado homogêneo, nas duas últimas décadas, houve predomínio no consumo de alimentos industrializados, comprados em supermercados, em todas as classes de rendas (Tardivo \& Falcão, 2006).

Ansaloni (2008) fez uma tentativa para explicar o aumento da obesidade na classe social de menor renda, ao considerar que o contexto em que está inserida uma grande parcela da população infantil brasileira permanece menos horas por dia em escolas públicas, enquanto seus responsáveis passam mais tempo fora de casa, entre trabalho e longos deslocamentos. Assim, os riscos da vida moderna mantêm essas crianças em casa, com pouca atividade física, suscetíveis às influências de uma TV que se tornou uma espécie de babá e professora. As mudanças ocorridas também contaram com a colaboração dos interesses das grandes indústrias em aumentar sua lucratividade, proporcionando um investimento maior no cenário de produtos voltados para a clientela infantil. McNael (1990) citou uma pesquisa, em 1984, com os maiores varejistas dos EUA, apontando que somente $1 / 3$ dos entrevistados buscavam atrair crianças como consumidores e aplicavam políticas e práticas de marketing aos clientes infantis. Em 1991, o estudo foi reaplicado e os resultados revelaram um aumento significativo nos interesses e investimentos desses varejistas para a clientela infantil.

Embora não existam estatísticas sobre a situação no Brasil, indicadores como renda per capita, população e PIB fornecem uma ideia próxima a quatro bilhões de dólares destinados somente a compras diretas infantis, e 120 bilhões em produtos adquiridos sob sua influência (Ansaloni, 2008). O mesmo autor afirmou que a mídia é considerada um meio de comunicação importante na formação dos hábitos alimentares infantis. Portanto, quanto mais jovem a criança, menos ela se cansa com a repetição desses comerciais, e mais acredita no que está vendo, tentando cumprir o que o anúncio lhe sugere. Assim, repetir por diversas vezes o comercial de TV aumenta sua preferência pelo produto anunciado. Na mesma linha de análise, comerciais de TV - pelos quais as crianças se interessam - podem alterar substancialmente suas preferências por categoria de produto e, assim, suas escolhas. Estudos conduzidos por McNeal $(1990,2000)$ salientaram que crianças entre 6 e 11 anos assistem à televisão por três ho- ras diárias, em média, que consiste em uma porção considerável de seu tempo livre. Crianças pertencentes a famílias de renda mais baixa assistem mais à TV em relação às crianças de famílias de classes média e alta. Ainda assim, deve-se reconhecer, na gênese da obesidade, a importância das preferências individuais passíveis da influência de experiências alimentares positivas e negativas vividas no cotidiano. À medida que a criança amplia seu leque de socialização, também se multiplicam as influências advindas dos tempos atuais. Halpern (2004), em outra pesquisa realizada em 2004, gravou a programação de três emissoras de televisão aberta, durante exibição de desenhos animados, programas de auditório e novelas por 30 dias. Os comercias de alimentos constituíram a maioria dos anúncios $(22 \%)$, à frente até das propagandas de brinquedos (15\%). Entre os alimentos anunciados, guloseimas como bolachas, doces e balas figuravam em primeiro lugar.

Em um dos seus trabalhos, na década de 1970, o estudioso do desenvolvimento infantil, Jean Piaget afirmou que crianças entre 2 e 7 anos de idade são mais sensíveis às influências externas e mais receptivas à propaganda, visto que suas estruturas cognitivas estão em formação. Nesse período, são fortemente influenciadas por imagens e processos simbólicos, inclusive a propaganda, e começam a fazer julgamentos sobre produtos que elas usariam no futuro (Piaget, 1970). Assim, a criança se insere no meio social e passa a influenciar o consumo da família numa via de mão dupla. As dificuldades do sistema familiar, nesse intercâmbio com o meio, acontecem quando o direcionamento do consumo se dá através da sedimentação de hábitos inadequados, formando, estrategicamente, consumidores fiéis por longos períodos de tempo. Complementando o poder da mídia e da propaganda, Wiecha (2006) citou o impacto da televisão na vida da criança:

Assistir à TV é um fator de risco para o excesso de peso por dois motivos: (1) uso sedentário do tempo e (2) eficácia da TV em fazer as crianças comerem alimentos que são anunciados, aumentando seu consumo total de calorias. (p. 438).

Soma-se às questões discutidas até agora, na instalação da obesidade, a redução da atividade física. De acordo com Bracco (2008), os seres humanos tiveram uma drástica redução do gasto calórico devido ao progresso tecnológico. Ainda, segundo a autora, vários estudiosos das áreas de biologia e antropologia concordam que, nos últimos 50 mil anos, o genoma humano apresentou mínimas alterações. Verificaram 
também que civilizações ancestrais de caçadores e agricultores apresentavam uma média de ingestão calórica de $3.000 \mathrm{kcal}$ contra $1.000 \mathrm{kcal}$, despendidas sob a forma de atividade física. Após o processo de industrialização, a média de ingestão caiu para 2.100 kcal, e de gasto energético para $300 \mathrm{kcal}$ diariamente.

As pessoas trocaram o caminhar e subir escadas pelo uso de automóveis, elevadores e escadas rolantes. A isso, alia-se a falta de segurança e de espaços públicos para o relacionamento e a recreação, gerando uma estrutura que provoca a exclusão, o que leva, cada vez mais, as pessoas para dentro de suas casas, buscando opções de lazer como o videogame, o computador e a televisão, que proporcionam o aumento da vida sedentária, afetando não somente os adultos, mas, principalmente, as crianças. Molina e Zanella (2005) acreditam que a prática da atividade física pode colaborar para o equilíbrio da massa corpórea, evitando o acúmulo ou excesso desta. Referiram também que ela reduz o risco cardiovascular, muito comum na população de obesos. Para os autores, a prática de exercícios melhora o controle glicêmico e a sensibilidade à insulina, contribuindo assim, para a redução da pressão arterial e para prevenção do diabete tipo 2.

Outro ponto para reflexão é o papel da escola no ensino-aprendizagem das práticas alimentares. Estudo realizado por Gaglianone (1999) demonstrou que o sistema educacional estava caracterizado pela má qualidade de ensino e pela falta de acesso correto ao uso social da informação, pois os conteúdos de educação nutricional, nos currículos das escolas fundamentais, encontravam-se incompletos e desatualizados, fornecendo conceitos errados sobre alimentação e o papel preventivo das doenças. Já em outro estudo realizado por Megid e Fracalanza (2003), os autores observaram que, no campo da alimentação, há uma inadequação dos livros didáticos, por não tratar de forma contextualizada o novo perfil de dieta da população brasileira (excesso de açúcar, condimentos, massa e seus derivados). Além disso, eles geram informações incorretas em relação aos conceitos básicos dos grupos alimentares para que ocorra uma dieta saudável por parte dos escolares. Acredita-se que o material escolar deve ser coerente com a proposta pedagógica do ensino, e levar a comunidade estudantil a se sentir motivada a refletir sobre o significado da saúde, discutindo sobre prevenções, causas e possíveis soluções para uma vida de qualidade.

Outro fator importante - que faz parte desse panorama alimentar - a que a família se encontra exposta são as contradições sociais presentes na cultura. En- quanto se estabelecem programas incentivando estilo de vida e hábitos alimentares saudáveis, não se deixa de comemorar os finais de semana com a feijoada do sábado e o churrasco do domingo, sem contar que, todo prazer e desprazer de um acontecimento na vida das pessoas, pode ser compensado com uma bebida, um doce ou um chocolate (Freitas, 2004). Esse fator salienta a ambiguidade das questões culturais presentes no cotidiano da população.

\section{CONSIDERAÇÕES FINAIS}

Não há dúvida de que a alimentação é essencial à sobrevivência do homem. É um ato inscrito na origem cultural humana desde os registros remotos da civilização. Apesar da existência de relatos, a partir da fase Paleolítica, sobre a prevalência da obesidade, ela nunca se apresentou em grau epidêmico como na atualidade. Os modos de vida foram modificados profundamente pelo progresso da urbanização, industrialização, profissionalização das mulheres, elevação do nível de vida e de educação. Outras mudanças sociais também contribuíram para o avanço da obesidade, como a transição alimentar, que atingiu seu apogeu através do aumento da renda média per capita e diminuição dos preços de alimentos ricos em gorduras e açúcares.

Nesse contexto, o sistema familiar teve que se adaptar às modificações geradas pelos novos modos de viver, como foi o caso da emancipação feminina, bem como o trabalho fora de casa, em que o tempo de preparo à disposição para aprontar os alimentos reduziu-se, levando ao aumento das ofertas e da demanda por comidas já prontas ou de preparação rápida, baratas e saborosas. Ocorre uma simplificação e homogeneização dos processos culinários e dos alimentos servidos acarretando em uma desritualização dos elementos de comunicação e intercâmbio humano às refeições.

Outro ponto interessante, é que a indústria, sabidamente, assumiu uma posição crescente na oferta de produtos na área alimentar, condicionando as exigências dos consumidores através da publicidade e de técnicas de mercado persuasivas, principalmente de produtos referentes à população infantil. Essas empresas perceberam que as crianças são mais receptivas a incorporar comportamentos aos quais estão expostas e, em um movimento de causalidade circular, acabam influenciando as escolhas da família.

Nota-se que o papel da escola é importante no desenvolvimento de uma alimentação adequada, visto 
que ela é peça fundamental, por exercer o papel de educadora. Mesmo diante do conhecimento de informações desatualizadas, presentes nos livros didáticos no Brasil, no que se refere aos alimentos, a escola e seus atores sociais continuam constituindo um espaço com condições de inspirar mudanças no comportamento e atitudes das crianças e de suas famílias.

Não se pode deixar de falar que os hábitos sedentários também desempenham papel importante na instalação da obesidade e, no que se refere às crianças, observa-se, cada vez mais, a tendência por divertimentos em que se gasta menos energia (videogames, computadores). O desenvolvimento tecnológico trouxe uma diminuição da necessidade de as pessoas se mexerem, e as classes desfavorecidas socialmente acabam sendo mais afetadas devido ao tempo gasto diante da televisão, por ser um divertimento mais acessível. Isso não quer dizer que a obesidade não afete também as camadas de renda mais elevada da população.

Nesse cenário, o lazer ativo que promova gasto de energia em praças e locais estruturados e com segurança aparece como um problema das cidades maiores, pois, para estimular uma melhoria nas condições sociais e ambientais é sabido que há uma necessidade de investimento de políticas públicas eficazes, o que não depende apenas do querer das famílias. No entanto, acredita-se que famílias, escolas, comunidades e profissionais de saúde são capazes de desenvolver ações integradas de conhecimentos e habilidades para a vida, proporcionando atuações de baixo custo e com amplo acesso a todas as camadas sociais, desenvolvendo reflexões críticas que possam auxiliar na prevenção da obesidade infantil.

\section{REFERÊNCIAS}

Ansaloni, J. A. (2008). Propaganda, transição nutricional e segurança alimentar na sociedade brasileira. In J. A. A. C. Taddei (Ed.), Jornadas científicas do NISAN: Núcleo Interdepartamental de Segurança Alimentar e Nutricional 2006/2007 (pp. 19- 32). Barueri: Minha Editora.

Ariès, P. (2006). História social da criança e da família (D. Flaksman, Trans.). Rio de Janeiro: LTC. (Trabalho original publicado em 1973)

Assumpção, F. B. J. (2004). A questão da beleza ao longo do tempo. In B. R. Salvador (Ed.), Anorexia, bulimia e obesidade (pp. 1-12). São Paulo: Manole.

Bracco, M. M. (2008). Atividade física como instrumento de promoção de saúde e cidadania. In J. A. A. C. Taddei (Ed.), Jornadas científicas do NISAN: Núcleo Interdepartamental de Segurança Alimentar e Nutricional 2006/2007 (pp. 251-263). São Paulo: Minha Editora.

Chaves, A. M., Borrione, R. T. M., \& Mesquita, G. R. (2004). Significado de infância: A proteção à infância oferecida pela
Santa Casa de Misericórdia na Bahia do século XIX. Interação em Psicologia, 8, 103-111. Retirado de http://ojs.c3sl.ufpr.br/ ojs2/index.php/psicologia/article/view/3244/2604

Collipp, P. J. (1977). Diagnóstico diferencial de obesidade infantil. In P. J. Collipp (Ed.), Tratamento da criança obesa (U. C. Arantes, Trans.) (pp. 27-46). São Paulo: Manole.

Espaço Ciência Viva (2010). Quando a alimentação vira um problema de saúde pública. Retirado de http://dc122.4shared. com/doc/PsDIkA9F/preview.html

Fisberg, M. (2004). Primeiras palavras: Uma introdução ao problema de peso excessivo. In M. Fisberg (Ed.), Atualização em obesidade na infância e adolescência (pp. 1-09). São Paulo: Atheneu.

Fischler, C. (1998). A "mcdonaldização" dos costumes. In J. L. Flandrin \& M. Montanari (Eds.), História da alimentação (L. V. Machado \& G. J. F. Texeira, Trans.) (pp. 841- 862). São Paulo: Estação Liberdade.

Franco, A. (2004). De caçador a gourmet: Uma história da gastronomia. São Paulo: Senac.

Freitas, K. M. C. (2004). Obesidade, mulher e família (Dissertação de mestrado). Universidade Católica de Pernambuco, Recife.

Gaglianone, C. P. (1999). Estudo do conteúdo relacionado à nutrição em livros didáticos de ciências utilizados no ensino médio fundamental brasileiro (Dissertação de mestrado). Universidade Federal de São Paulo.

Garcia, R. W. D. (2003). Reflexos da globalização na cultura alimentar: Considerações sobre as mudanças na alimentação urbana. Revista Nutrição, 16, 483- 492. Retirado de http:// www.scielo.br/scielo.php?pid=S1415-52732003000400011 \&script $=$ sci_arttext

Góes, J. A. V. (2005). Mudanças de hábitos alimentares e saúde: Um estudo em fast-food (Tese de doutorado). Universidade Federal da Bahia, Salvador.

Halpern, G. (2004). Comerciais veiculados em programação infanto-juvenil de canais abertos de TV e sua relação com escolha de alimentos em amostras de escolares (Dissertação de mestrado). Universidade Federal de São Paulo.

Instituto Brasileiro de Geografia e Estatística (2004). Pesquisa de orçamentos familiares. Retirado de http://www.ibge.gov.br/ home/presidencia/noticias/noticia_impressao.php?id_noticia $=171$

Jablonsky, B. (2007). O cotidiano do casamento contemporâneo: A difícil e conflitiva divisão de tarefas e responsabilidades entre homens e mulheres. In C. T. Fères (Ed.), Família e casal: Saúde, trabalho e modos de vinculação (pp. 203-228). São Paulo: Casa do Psicólogo.

Levenstein, H. A. (1998). Dietética contra gastronomia: Tradições culinárias, santidade e saúde nos modelos de vida americanos. In J. L. Flandrin \& M. Montanari (Eds.), História da alimentação (L. V. Machado \& G. J. F. Texeira, Trans.) (pp. 825- 840). São Paulo: Estação Liberdade.

Levenstein, H. A. (2003). Paradox of plenty: A social history of eating in modern America. Berkeley, CA: University of California Press.

Levenstein, H. A. (2003). Revolution at the table: The transformation of the American diet. Berkeley, CA: University of California Press.

Megid, J. N., \& Fracalanza, H. (2003). O livro didático de ciências: Problemas e soluções. Ciência \& Educação, 9, 147-157. Retirado de http://www.scielo.br/pdf/ciedu/v9n2/01.pdf 
Molina, S. J., \& Zanella, M. T. (2005). Atividade física no tratamento da obesidade. In A. M. Claudino \& M. T. Zanella (Eds.), Guia de transtornos alimentares e obesidade (pp. 253-258). São Paulo: Manole.

Monteiro, C. A., \& Conde, W. L. (1999). A tendência secular da obesidade segundo estratos sociais: Nordeste e Sudeste do Brasil, 1975-1989-1997. Arquivos Brasileiros de Endocrinologia \& Metabologia, 43, 186-194. Retirado de http://www.scielo.br/ scielo.php?script=sci_arttext\&pid=S0004-27301999000300004

McNael, J. (1990). Children as consumers: Insight and implications. Lanham, MD: Lexington Books.

McNael, J. (2000). Children as consumers of commercial and social products. Washington, DC: OPAS.

Novaes, J. V. (2010). Com que corpo eu vou? Sociabilidade e usos do corpo nas mulheres de camadas altas e populares. Rio de Janeiro: Pallas.

Organização Mundial de Saúde (2006). Obesidade e sobrepeso. Retirado de http://www.who.int/mediacentre/factsheets/fs311/ en/index.html

Perlés, C. (1998). As estratégias alimentares nos tempos préhistóricos. In J. L. Flandrin \& M. Montanari (Eds.), História da alimentação (L. V. Machado \& G. J. F. Teixeira, Trans.) (pp. 36- 53). São Paulo: Estação Liberdade.

Piaget, J. (1970). O nascimento da inteligência da criança (A. Cabral, Trans.). Rio de Janeiro: Zahar.

Philippi, S. T. (2008). Estratégias de intervenção nutricional para promoção da saúde e redução do risco de anemia carencial: $\mathrm{O}$ papel da educação nutricional. In J. A. A. C. Taddei (Ed.), Jornadas Científicas do NISAN: Núcleo Interdepartamental de Segurança Alimentar e Nutricional 2006/2007 (pp. 125-140). São Paulo: Minha Editora.
Ramos, P., \& Storel, A. O. J. (2001). O açúcar e as transformações nos regimes alimentares. Cadernos de Debate, 8, 36-55. Retirado de http://www.unicamp.br/nepa/arquivo_san/O_Acucar_ e_as_Transformacoes_nos_Regimes_Alimentares.pdf

Setian, N. (2007). Obesidade na criança e no adolescente: Buscando caminhos desde o nascimento. In N. Setian (Ed.), Obesidade na criança e no adolescente: Buscando caminhos desde o nascimento (pp. 1-05). São Paulo: Roca.

Tardivo, A. P., \& Falcão, M. C. (2006). O impacto da modernização na transição nutricional e obesidade. Revista Brasileira de Nutrição Clínica, 21, 117-124.

Tonial, S. R. (2001). Desnutrição e obesidade: Faces contraditórias na miséria e na abundância. Recife: Instituto Materno Infantil de Pernambuco.

Vasconcellos, M. J. E. (2009). Pensamento sistêmico: $O$ novo paradigma da ciência. Campinas: Papirus. (Trabalho original publicado em 2003)

Weinberg, C. (2010). Do ideal ascético ao ideal estético: A evolução histórica da anorexia nervosa. Revista Latinoamericana de Psicopatologia Fundamental, 13, 224-237.

Wiecha, J. L. (2006). When children eat what they watch: Impact of television viewing on dietary intake in youth. Archives of Pediatrics \& Adolescent Medicine, 160, 436-442. 